\title{
Radiative effects of ozone on the climate of a Snowball Earth
}

\author{
J. Yang ${ }^{1}$, Y. Hu ${ }^{1}$, and W. R. Peltier ${ }^{2}$ \\ ${ }^{1}$ Laboratory for Climate and Ocean-Atmosphere Studies, Department of Atmospheric and Oceanic Sciences, \\ School of Physics, Peking University, Beijing, China \\ ${ }^{2}$ Department of Physics, University of Toronto, Toronto, Ontario, Canada \\ Correspondence to: Y. Hu (yyhu@pku.edu.cn)
}

Received: 27 July 2012 - Published in Clim. Past Discuss.: 14 August 2012

Revised: 20 November 2012 - Accepted: 28 November 2012 - Published: 10 December 2012

\begin{abstract}
Some geochemical and geological evidence has been interpreted to suggest that the concentration of atmospheric oxygen was only $1-10 \%$ of the present level in the time interval from 750 to 580 million years ago when several nearly global glaciations or Snowball Earth events occurred. This low concentration of oxygen would have been accompanied by a lower ozone concentration than exists at present. Since ozone is a greenhouse gas, this change in ozone concentration would alter surface temperature, and thereby could have an important influence on the climate of the Snowball Earth. Previous works that have focused either on initiation or deglaciation of the proposed Snowball Earth has not taken the radiative effects of ozone changes into account. We address this issue herein by performing a series of simulations using an atmospheric general circulation model with various ozone concentrations.

Our simulation results demonstrate that, as ozone concentration is uniformly reduced from $100 \%$ to $50 \%$, surface temperature decreases by approximately $0.8 \mathrm{~K}$ at the Equator, with the largest decreases located in the middle latitudes reaching as high as $2.5 \mathrm{~K}$. When ozone concentration is reduced and its vertical and horizontal distribution is simultaneously modulated, surface temperature decreases by $0.4-$ $1.0 \mathrm{~K}$ at the Equator and by $4-7 \mathrm{~K}$ in polar regions. These results here have uncertainties, depending on model parameterizations of cloud, surface snow albedo, and relevant feedback processes, while they are qualitatively consistent with radiative-convective model results that do not involve such parameterizations and feedbacks. These results suggest that ozone variations could have had a moderate impact on the climate during the Neoproterozoic glaciations.
\end{abstract}

\section{Introduction}

Two important Earth evolutionary processes coincided in the Neoproterozoic era. One of these may have involved a further rise of atmospheric oxygen $\left(\mathrm{O}_{2}\right)$ from $\sim 1 \%$ to $\sim 10 \%$ of the present atmospheric level (PAL) during the period from 750 to 580 million years ago (Ma) (Canfield, 2005; Catling and Claire, 2005; Holland, 2006). The second important process that occurred in this interval of time involved the occurrence of global-scale glaciations, the so-called "Snowball Earth" events (at least two of which, i.e. the Sturtian glaciation at $\sim 716 \mathrm{Ma}$ and the Marinoan glaciation at $\sim 635 \mathrm{Ma}$, are widely believed to have occurred. See Pierrehumbert et al., 2011, for a recent review). These two evolutionary processes must be connected through biogeochemical and geological mechanisms, as integral parts of the evolution of the Earth system, although the coupling mechanisms remain obscure. Here, we present results of numerical simulations suggesting that the primary product of the photolysis of oxygen, namely ozone $\left(\mathrm{O}_{3}\right)$, could have exerted an important influence on both initiation and deglaciation of the Snowball Earth through the influence of radiative transfer processes.

According to the standard Snowball Earth hypothesis (Kirschvink, 1992; Hoffman et al., 1998; Hoffman and Schrag, 2002), initiation and deglaciation of the Snowball Earth are associated with changes in the carbon dioxide $\left(\mathrm{CO}_{2}\right)$ concentration between extremely low and extremely high levels as a consequence of the action of the carbonate-silicate cycle. Simulations with energy balance models (EBMs) and general circulation models (GCMs) yield different $\mathrm{CO}_{2}$ thresholds for initiating the Snowball Earth (Chandler and Sohl, 2000; Hyde et al., 2000; Poulsen et al., 2001; Donnadieu et al., 2004; Poulsen and Jacob, 2004; 
Lewis et al., 2007; Peltier et al., 2007; Liu and Peltier, 2010, 2011; Pierrehumbert et al., 2011). Several recent studies with fully coupled atmosphere-ocean models have suggested that the $\mathrm{CO}_{2}$ threshold is quite strongly model dependent, ranging from 17.5-20 ppmv in CCSM3 (Yang et al., 2012a,b), 86 ppmv in MIROC-lite (Oka et al., 2010), 70-100 ppmv in CCSM4 (Yang et al., 2012c), to 278 ppmv in ECHAM5/MPIOM (Voigt and Marotzke, 2010; Voigt et al., 2011), when there is a $6 \%$ reduction in solar luminosity. For deglaciation is assumed, simulations with different models have also suggested different thresholds (Hyde et al., 2000; Tajika, 2003; Pierrehumbert, 2004, 2005; Le Hir et al., 2007). The most recent study of $\mathrm{Hu}$ et al. (2011a) showed that the $\mathrm{CO}_{2}$ threshold is approximately 0.21 bars in a radiative-convective model and approximately 0.38 bars in a GCM when pressurebroadening and collision-induced absorption of $\mathrm{CO}_{2}$ at high pressure and high levels of $\mathrm{CO}_{2}$ are taken into account. With the assumption of a dust zone at the surface in the tropics, which would lower tropical surface albedo, the $\mathrm{CO}_{2}$ threshold required to trigger the deglaciation would drop to approximately 0.1 bar (Abbot and Pierrehumbert, 2010; Le Hir et al., 2010; Li and Pierrehumbert, 2011).

It is important to note that all of the simulations discussed above have simply employed the present-day $\mathrm{O}_{3}$ level as default (e.g. Poulsen et al., 2001; Voigt and Marotzke, 2010; Pierrehumbert et al., 2011; Hu et al., 2011a; Yang et al., 2012a,b,c) and have furthermore neglected the fact that $\mathrm{O}_{3}$ concentration for both the stratosphere and the troposphere in the Neoproterozoic era could have been significantly lower than the present-day level, which could significantly alter the $\mathrm{CO}_{2}$ thresholds for both initiation and deglaciation of the Snowball Earth as we will show below.

In the present-day atmosphere, the ozone layer is mainly located in the stratosphere approximately between 10 and $50 \mathrm{~km}$ in altitude, with peak concentration at about $25 \mathrm{~km}$ high. It is well known that $\mathrm{O}_{3}$ absorbs solar ultraviolet radiation, which protects life on the surface. On the other hand, $\mathrm{O}_{3}$ also has a strong absorption band in the infrared region $(9.6 \mu \mathrm{m})$. Thus, ozone is a greenhouse gas. The radiative effect of $\mathrm{O}_{3}$ on the troposphere and surface is two-fold. First, solar absorption of the ozone layer directly cools the troposphere and surface. Downward infrared emission by $\mathrm{O}_{3}$, on the other hand, warms the troposphere and surface. There is also an indirect effect of other stratospheric greenhouse gases (e.g. $\mathrm{CO}_{2}$ and $\mathrm{H}_{2} \mathrm{O}$ ) on the troposphere and surface. That is, the $\mathrm{CO}_{2}$ and $\mathrm{H}_{2} \mathrm{O}$ down-emission of energy, which was deposited in the stratosphere due to $\mathrm{O}_{3}$ solar and infrared absorption, also warm the troposphere and surface. It was estimated that about $50 \%$ of the $\mathrm{CO}_{2}$ and $\mathrm{H}_{2} \mathrm{O}$ downemission is due to $\mathrm{O}_{3}$ solar and infrared absorption, and that the net radiative effect of stratospheric $\mathrm{O}_{3}$ is to warm the troposphere and surface by about $2.4 \mathrm{~W} \mathrm{~m}^{-2}$ (Ramanathan and Dickinson, 1979). Therefore, a decline of stratospheric ozone concentration would decrease stratospheric temperature and reduce the downward emission of infrared radiation, causing a cooling of the troposphere and surface (Forster and Shine, 1997; Hu et al., 2011b). Indeed, studies with onedimensional (1-D) radiative-convective models and GCMs have all shown that ozone depletion from the late 1970s to the late 1990s did in fact cause a cooling of the troposphere and surface by offsetting greenhouse warming, and ozone recovery in the 21 st century may enhance greenhouse warming (e.g. Ramaswamy et al., 1992; Hu and Tung, 2003; Hu et al., 2005, 2011b; Cordero and Forster, 2006; Gauss et al., 2006). For tropospheric ozone, it leads to more solar and longwave radiation being absorbed in the troposphere and gives a positive forcing on the surface. Hence, changes in tropospheric ozone concentration also will change the radiative energy absorption of the Earth/atmosphere system and thereby also change the surface air temperature (e.g. Fishman et al., 1979; Forster et al., 1996; Gauss et al., 2006).

According to results from photochemical models (Segura et al., 2003), a 100-fold decrease in atmospheric $\mathrm{O}_{2}$ from $100 \%$ to $1 \%$ PAL would cause a reduction in total column ozone depth by about two-thirds, and ozone concentration decreases for both the troposphere and the stratosphere. In addition to ozone concentration, the spatial distribution of ozone in the Neoproterozoic era may also have been considerably different from present. First, the ozone layer would be lower in altitude (see Fig. 2b in Segura et al., 2003). This would lead to a relatively strong (weak) greenhouse effect in the troposphere (stratosphere). Second, the horizontal distribution of stratospheric ozone would also be expected to be considerably different from present. Ozone is generated in the tropical stratosphere and transported to mid- and highlatitudes by the Brewer-Dobson circulation, which is forced by atmospheric wave-mean flow interaction processes (e.g. Holton et al., 1995). As a result, the maximum total column ozone is located in the subpolar regions in both hemispheres under present-day conditions. In contrast, total column ozone is relatively low in the tropics because of the more efficient rates of ozone photolysis that occurs in this region. GCM simulations have shown that wave activity under Snowball Earth conditions is much weaker than that under presentday conditions (Pierrehumbert, 2005), suggesting that there would be less ozone transported to high latitudes in the Neoproterozoic era. Thus, reductions of ozone at high latitudes would be expected to be greater than at low latitudes.

The goal of the present work is to investigate the radiative effect of ozone on the climate of Neoproterozoic Snowball Earth conditions and its implications for the initiation and deglaciation of a hard Snowball Earth. The paper is organized as follows: Sect. 2 describes the climate model employed in the analyses and the design of the numerical experiments we have performed to test the sensitivity of climate to the expected variations in ozone amount and distribution. Simulation results are presented in Sect. 3. We will show surface and air temperature responses to various ozone concentrations and spatial distributions and analyze the changes in radiative 
fluxes and the feedbacks associated with snow albedo, water vapor and clouds. Conclusions are summarized in Sect. 4.

\section{Model description and experimental design}

The model we have employed is the Community Atmosphere Model version 3 (CAM3) developed at the National Center for Atmospheric Research (NCAR). It is based on a Eulerian spectral dynamical core with triangular spectral truncation at 42 wave-numbers and 26 vertical levels from the surface to approximately $2.0 \mathrm{hPa}$, and it has a horizontal resolution of approximately $2.8^{\circ}$ by $2.8^{\circ}$ (Collins et al., 2004). The sea-ice component includes an energy-conserving thermodynamic model (Briegleb et al., 2004). To simulate a hard Snowball Earth climate, we prescribe an ocean with a fixed sea-ice thickness of $15 \mathrm{~m}$, but snow depth and surface temperature are predicted. Snow depth varies with time, depending on the hydrological cycle, and surface temperature is determined by the surface energy budget. The sea-ice/snow prescription employed herein is similar to that in Le Hir et al. (2007) and $\mathrm{Hu}$ et al. (2011a).

In the simulations, the entire surface is covered by seaice/snow and no continents are included. As surface temperature $\left(T_{\mathrm{S}}\right)$ is equal to or less than $-1{ }^{\circ} \mathrm{C}$, sea-ice albedo and snow albedo are 0.50 and 0.78 , respectively. When $T_{\mathrm{S}}$ increases from $-1{ }^{\circ} \mathrm{C}$ to $0{ }^{\circ} \mathrm{C}$, sea-ice albedo and snow albedo decrease by 0.075 and 0.124 , respectively. $\mathrm{CO}_{2}$ concentration is set to either $100 \mathrm{ppmv}$ or 0.1 bar. Methane concentration is $1.714 \mathrm{ppmv}$; nitrous oxide concentration is $0.311 \mathrm{ppmv}$; and the concentrations of both aerosols and $\mathrm{CFCs}$ are set to zero. Surface pressure is fixed at $1.0 \mathrm{bar}$; the influence of pressure broadening associated with a high level of $\mathrm{CO}_{2}$, as discussed in $\mathrm{Hu}$ et al. (2011a), can be safely ignored in these simulations. Solar luminosity is fixed at $94 \%$ of the present-day level, i.e. $1283 \mathrm{~W} \mathrm{~m}^{-2}$. Earth's orbital parameters are fixed to the present values (year 1950).

The simulations we have performed are designed to test five different ozone scenarios. (1) The "control" experiment with the present-day ozone layer is specified on the basis of the assumption of current monthly but zonally symmetric variations, the same as that employed in the Atmospheric Model Intercomparison Project II (Wang et al., 1995) (Fig. 1a, in units of partial pressure, i.e. mPa). (2) Ozone concentrations of both the stratosphere and the troposphere are uniformly reduced to $50 \%$ of the present-day level, which we will refer to in what follows as the " $50 \%$ " scenario (Fig. 1b). (3) The ozone layer is shifted downward at all latitudes by approximately $4 \mathrm{~km}$, to be referred to as the "lower" scenario (Fig. 1c). (4) The ozone concentration is scaled in the region poleward of $30^{\circ} \mathrm{S}(\mathrm{N})$ by a function of $\cos (\varphi)$ ( $\varphi$ is latitude), representing the influence of the relatively weak BrewerDobson circulation expected to exist in the extremely cold climate state of a Snowball Earth, to be referred to as the "WBD" scenario (Fig. 1d). (5) The ozone concentration is decreased as in (2), and its vertical and meridional distribution is simultaneously modulated as in (3) and (4), to be referred to as the "50\%_Lower_WBD" scenario (Fig. 1e). Sequences of 60-yr simulations were performed for each ozone scenario, initialized with the present-day climate; the last $5 \mathrm{yrs}$ of which were employed as the basis for analysis.

\section{Results}

\subsection{Changes of surface and air temperatures}

In the Snowball Earth state with unperturbed ozone, annualand zonal-mean surface air temperature $\left(T_{\mathrm{S}}\right)$ is as low as $220 \mathrm{~K}$ in global mean and $240 \mathrm{~K}$ at the Equator, due to high sea-ice/snow albedo and weak water vapor and cloud greenhouse effects (Pierrehumbert, 2004, 2005; Le Hir et al., 2007; $\mathrm{Hu}$ et al., 2011a). Figure 2 illustrates the changes of $T_{\mathrm{S}}$ for the different ozone scenarios. Under the assumption of a $\mathrm{CO}_{2}$ level of $100 \mathrm{ppmv}$, as ozone concentration is uniformly decreased from $100 \%$ to $50 \%$ from the surface to the top of the model, $T_{\mathrm{S}}$ is predicted to cool at all latitudes. In global mean, $T_{\mathrm{S}}$ decreases by $0.8 \mathrm{~K}$. In the tropics between $30^{\circ} \mathrm{S}$ and $30^{\circ} \mathrm{N}$, surface cooling ranges from 0.4 to $1.0 \mathrm{~K}$. The maximum cooling occurs at $45^{\circ} \mathrm{S}$, with changes extending to $2.5 \mathrm{~K}$. The maximum cooling is caused by a strong snowalbedo feedback that we will address in detail in Sect. 3.2 below.

As the height of the ozone layer is lowered (the "lower" scenario), ozone concentration in the troposphere increases especially for the upper troposphere, which gives a positive forcing on the surface. As a consequence, the surface temperature increases at all latitudes, except for polar regions. The maximum warming occurs in the subpolar regions of both hemispheres, with a value of approximately $1.5 \mathrm{~K}$ (Fig. 2b).

In the case of the "WBD" scenario, ozone concentration is largely reduced at high latitudes, but has nearly nochange in the tropical region. Thus, $T_{\mathrm{S}}$ decreases at high latitudes and exhibits relatively small changes at low latitudes (Fig. 2c). When ozone concentration is reduced and its vertical and horizontal distribution is simultaneously modified (the "50\%_Lower_WBD" scenario), $T_{\mathrm{S}}$ decreases over almost all of the surface and the maximum cooling occurs in the polar regions, with maximum cooling as high as $4 \mathrm{~K}$ (Fig. 2d). In global mean, changes of surface air temperature are $-0.8,0.3,-0.4$, and $-0.8 \mathrm{~K}$ for the four different scenarios: $50 \%$, lower, WBD and 50_Lower_WBD, respectively.

To illustrate temperature responses to ozone changes at all levels, we plot height-latitude cross sections of annual- and zonal-mean air temperature for the control experiment and temperature differences between all other scenarios and the control experiment in Fig. 3. In the Snowball Earth climate state, the tropopause is much lower than that under present conditions, shifting to $\sim 200 \mathrm{hPa}$ level from $\sim 100 \mathrm{hPa}$ level over the Equator. $\mathrm{As}_{3}$ is uniformly reduced from $100 \%$ 

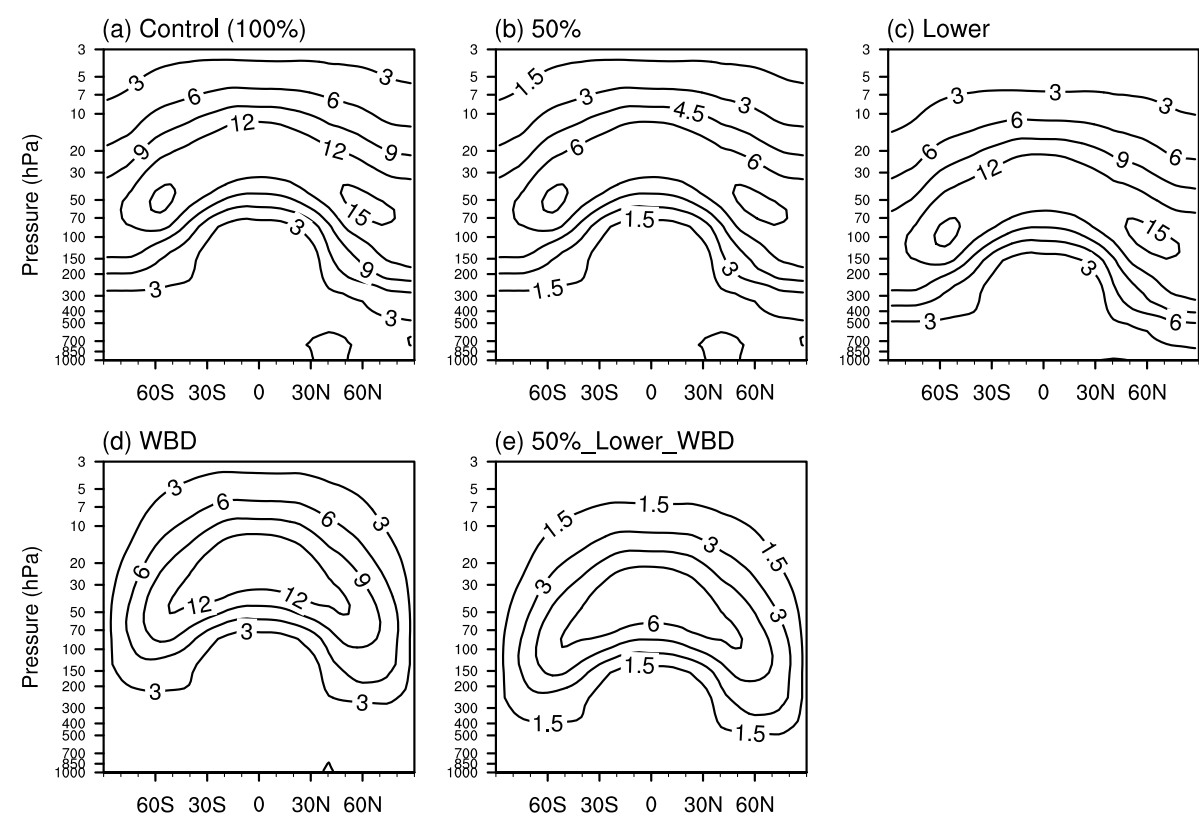

Fig. 1. Vertical cross-sections of annual- and zonal-mean $\mathrm{O}_{3}$ concentration for different scenarios (units: $\mathrm{mPa}$ ). (a) control (100\%), (b) $50 \%$, (c) lower, (d) WBD, and (e) 50\%_Lower_WBD. See text for detailed descriptions. Contour intervals are 3, 1.5, 3, 3 and 1.5 mPa, respectively.
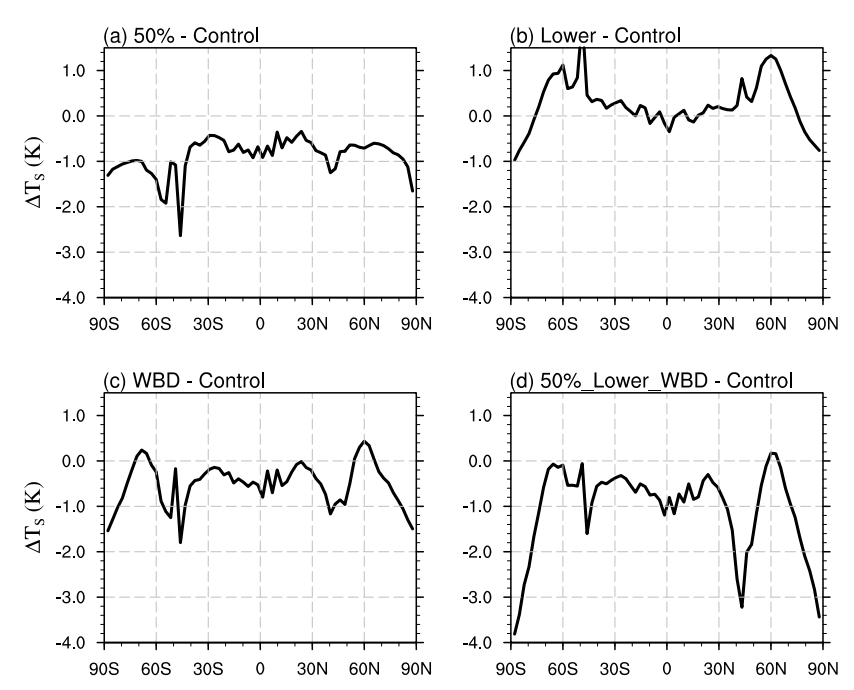

Fig. 2. Differences of annual- and zonal-mean surface air temperatures between various ozone scenarios and the control experiment for $100 \mathrm{ppmv}$ of $\mathrm{CO}_{2}$. (a) $50 \%$, (b) lower, (c) WBD, and (d) $50 \%$ Lower_WBD.

to $50 \%$, air temperatures of both the troposphere and the stratosphere are decreased. The decrease in air temperature increases with altitudes below $20 \mathrm{hPa}$, where a maximum cooling of approximately $13 \mathrm{~K}$ occurs. The cooling in the stratosphere is due to the fact that less ultraviolet radiation is absorbed, while cooling in the troposphere is caused by decreased downward infrared radiation from the stratosphere to the troposphere, the tropospheric $\mathrm{O}_{3}$ reduction, and water-vapor feedback (see Sect. 3.2 below). Lowering the elevation of the ozone layer is equivalent to increasing ozone in the troposphere and lower stratosphere and reducing ozone in the middle and upper stratosphere. As a result, the middle and upper stratosphere are cooled and the troposphere and lower stratosphere are warmed (Fig. 3c). For the "WBD" scenario, decreases in ozone concentration lead to cooling in mid- and high- latitudes of both the troposphere and the stratosphere (Fig. 3d). The maximum cooling is approximately $7 \mathrm{~K}$ at $50 \mathrm{hPa}$ over polar regions. For the " $50 \%$ Lower_WBD" scenario, air temperatures decrease in both the stratosphere and the troposphere, except for the slight increase in the tropical upper troposphere (Fig. 3e), which is a result of the balance between the downward shift of the ozone layer and the decrease in ozone concentration.

\subsection{Radiative fluxes and feedbacks}

Changes in surface and tropospheric temperatures are not only due to the direct radiative effect of ozone changes but also due to feedback processes. In the following, we first analyze radiative fluxes at the tropopause and at the surface and then show how feedbacks associated with water vapor, surface albedo, and clouds influence surface and air temperatures. Figure $4 \mathrm{a}$ shows the radiative effect of the stratosphere on the troposphere-surface system in the experiment with unperturbed ozone and $100 \mathrm{ppmv} \mathrm{CO}_{2}$. Here, the stratosphere is defined as the layer between the top of the model $(2 \mathrm{hPa})$ and the level of $170 \mathrm{hPa}$, which includes most of the ozone layer. The reason why we choose the $170 \mathrm{hPa}$ pressure level as the "tropopause" is because the model has 

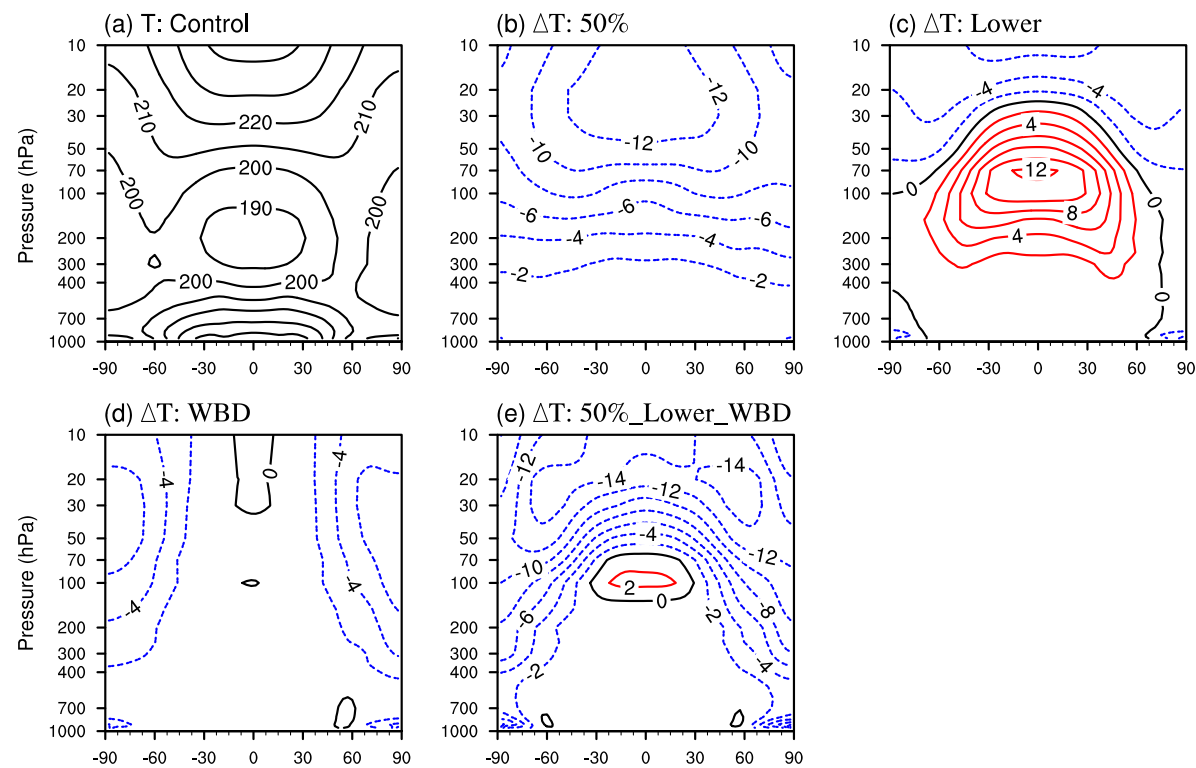

Fig. 3. Vertical cross-sections of annual- and zonal-mean air temperatures with the present-day ozone (a) and temperature differences between various ozone scenarios and the control experiment. (b) $50 \%$, (c) lower, (d) WBD, and (e) $50 \%$ _Lower_WBD. The CO 2 level is 100 ppmv. Contour intervals are $10 \mathrm{~K}$ in (a) and $2 \mathrm{~K}$ in (b-e).

been modified to have output of radiation fluxes at this pressure level, which simplifies diagnostics of radiation fluxes. Using the standard definition of the tropopause would not change our main conclusions. The shortwave radiation flux at the tropopause is negative, about $-4.6 \mathrm{~W} \mathrm{~m}^{-2}$, which is due to absorption of ultraviolet radiation by stratospheric $\mathrm{O}_{3}$. The longwave radiation flux is about $8.7 \mathrm{~W} \mathrm{~m}^{-2}$, which is the downward infrared emission by stratospheric greenhouse gases (e.g. $\mathrm{O}_{3}, \mathrm{CO}_{2}, \mathrm{H}_{2} \mathrm{O}, \mathrm{CH}_{4}$, and $\mathrm{N}_{2} \mathrm{O}$ ). Thus, the net radiative forcing of the stratosphere on the troposphere is $4.1 \mathrm{~W} \mathrm{~m}^{-2}$ warming in global and annual mean. This value is much smaller than that in the model with present-day conditions $\left(9.7 \mathrm{~W} \mathrm{~m}^{-2}\right.$; see Table 1). It is because (a) solar luminosity in the Neoproterozoic era was approximately $6 \%$ less than present; (b) surface albedo of the Snowball Earth is much higher than that on the present-day Earth (approximately 0.6 vs. 0.3 ), which weakens the radiative effect of the stratosphere on the troposphere in the shortwave band; and (c) the stratospheric temperature in the Snowball Earth climate state is much lower than present, and the downward infrared radiation from the stratosphere to the troposphere is thus much weaker. Results of other experiments with different ozone scenarios and $\mathrm{CO}_{2}$ levels are also listed in Table 1 for the global and annual mean.

As stratospheric $\mathrm{O}_{3}$ concentration is reduced, solar absorption by stratospheric $\mathrm{O}_{3}$ decreases, resulting in more shortwave radiation (ultraviolet radiation) reaching the troposphere. On the other hand, stratospheric temperature decreases, causing less downward infrared radiation to the troposphere. The net radiative forcing of the stratosphere on
Table 1. Comparison of radiative effects of the stratosphere on the troposphere between the present Earth and the Snowball Earth with different ozone scenarios (see text for details). The stratosphere here is defined as the layer between the top of the model $(2.0 \mathrm{hPa})$ and the level of $170 \mathrm{hPa}$. All of the values are for global and annual mean.

\begin{tabular}{lcccc}
\hline Experiments & $\begin{array}{c}\mathrm{SW}^{\mathrm{a}} \\
\left(\mathrm{W} \mathrm{m}^{-2}\right)\end{array}$ & $\begin{array}{c}\mathrm{LW}^{\mathrm{b}} \\
\left(\mathrm{W} \mathrm{m}^{-2}\right)\end{array}$ & $\begin{array}{c}\mathrm{Net}^{\mathrm{c}} \\
\left(\mathrm{W} \mathrm{m}^{-2}\right)\end{array}$ & $\begin{array}{c}\left.\Delta T_{\mathrm{S}} \mathrm{d}^{\mathrm{K}}\right) \\
(\mathrm{K})\end{array}$ \\
\hline $\begin{array}{l}\text { Present Earth: } \\
\text { RD79 }\end{array}$ & -7.2 & 17.4 & 10.2 & \\
$\mathrm{CAM3}^{\mathrm{f}}$ & -7.9 & 17.6 & 9.7 & \\
Snowball, 100 ppmv CO $2:$ & & & & \\
$100 \%$ & -4.6 & 8.7 & 4.1 & \\
$50 \%$ & -3.2 & 6.8 & 3.6 & -0.8 \\
Lower & -4.7 & 9.6 & 4.9 & 0.3 \\
WBD & -4.3 & 8.2 & 3.9 & -0.4 \\
50\%_Lower_WBD & -3.2 & 6.9 & 3.7 & -0.8 \\
Snowball, 0.1 bar CO $2:$ & & & & \\
100\% & -5.4 & 14.8 & 9.4 & \\
50\%_Lower_WBD & -3.9 & 12.8 & 8.9 & -1.0 \\
\hline
\end{tabular}

${ }^{\text {a }} \mathrm{SW}$ is shortwave absorption of the stratosphere multiplied by tropospheric co-albedo (1.0 minus the albedo at the tropopause). ${ }^{\mathrm{b}} \mathrm{LW}$ is downward longwave emission from the stratosphere to the troposphere. ${ }^{\mathrm{c}}$ Net is SW plus LW. ${ }^{\mathrm{d}} \Delta T_{\mathrm{S}}$ is the change of surface air temperature, relative to the control experiment with $100 \%$ ozone. ${ }^{\mathrm{e}} \mathrm{RD} 79$ is the result from a radiative-convective model obtained by

Ramanathan and Dickinson (1979). ${ }^{\mathrm{f}}$ CAM3 is the result obtained with the model's default present-day atmospheric conditions.

the troposphere, therefore, depends on the balance of the two opposite effects. In previous 1-D radiative-convective model calculations (Ramanathan and Dickinson, 1979; Fels et al., 1980; Forster and Shine, 1997), it was demonstrated that the longwave forcing plays the dominant role, and that the net energy input from the stratosphere to the troposphere 
(a) Control

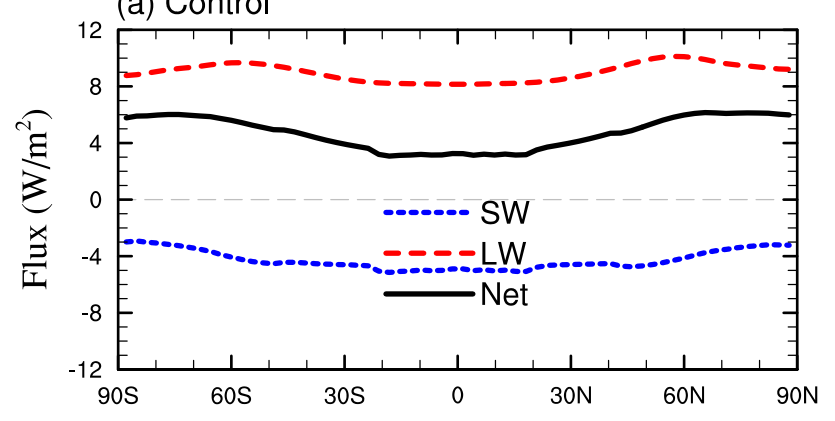

(b) $50 \%$ - Control
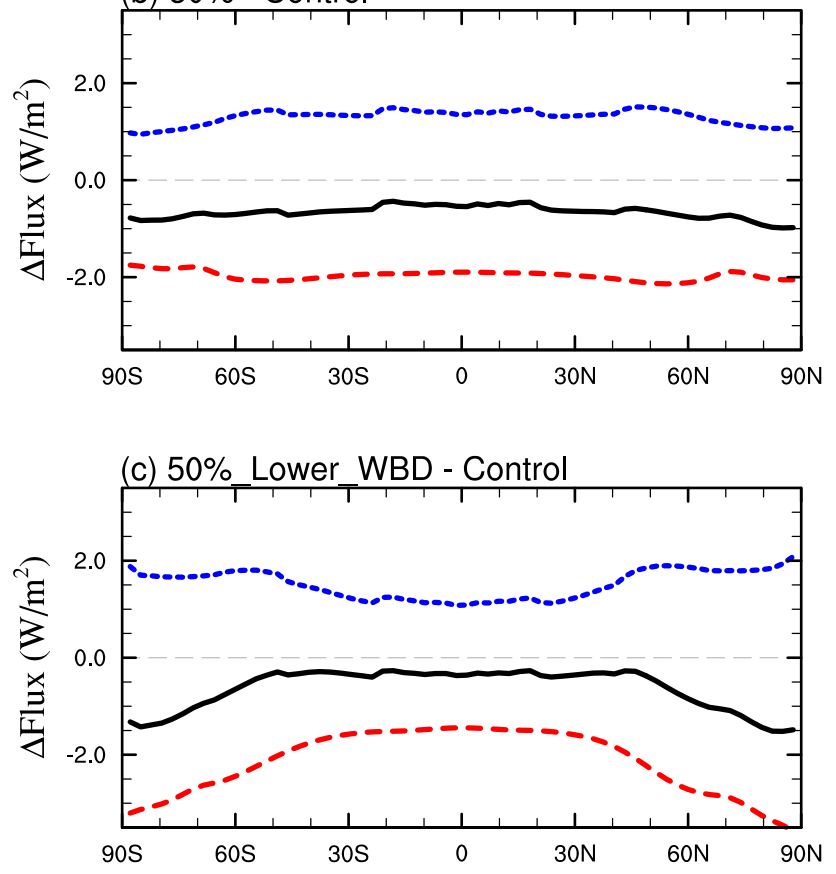

Fig. 4. Troposphere-surface radiative energy input under Snowball Earth conditions and $100 \mathrm{ppmv}$ of $\mathrm{CO}_{2}$. (a) the control experiment, (b) differences for the $50 \%$ scenario, and (c) differences for the $50 \%$ Lower_WBD scenario. SW is shortwave absorption by the stratosphere multiplied by tropospheric co-albedo. The tropospheric co-albedo is 1.0 minus the albedo at the tropopause. That is, only a part of the shortwave absorption by the stratosphere is meaningful for the troposphere and surface, and the remainder would be scatted/reflected back to space by the troposphere and surface if there were no stratosphere (see Ramanathan and Dickinson, 1979). LW is downward longwave emission at the tropopause. Net is SW plus LW.

decreases for stratospheric ozone reduction for the presentday climate, especially for ozone reduction in the lower stratosphere. This conclusion also applies to the Snowball Earth climate, as shown in Fig. 4b, c and Table 1. As ozone concentration is uniformly decreased from $100 \%$ to $50 \%$ with 100 ppmv of $\mathrm{CO}_{2}$, the global- and annual-mean radiation flux from the stratosphere to the troposphere is increased by about $1.4 \mathrm{~W} \mathrm{~m}^{-2}$ in shortwave radiation and is decreased by about $1.9 \mathrm{~W} \mathrm{~m}^{-2}$ in longwave radiation. The net change of radiation flux is about $-0.5 \mathrm{~W} \mathrm{~m}^{-2}$. In the case of the "50\%_Lower_WBD" ozone scenario, changes in shortwave and longwave radiation fluxes from the stratosphere to the troposphere are about 1.4 and $-1.8 \mathrm{~W} \mathrm{~m}^{-2}$, respectively, and the net change in radiation flux is about $-0.4 \mathrm{~W} \mathrm{~m}^{-2}$. The greatest decrease in net radiation flux occurs in the polar regions, with values of about $-1.5 \mathrm{~W} \mathrm{~m}^{-2}$ (Fig. 4c), due to the fact that in this scenario the most significant decrease of ozone concentration is within the polar regions. This is consistent with the largest decreases in surface and tropospheric temperatures in polar regions shown in Figs. $2 d$ and $3 e$.

In the above, we analyzed radiation fluxes at the "tropopause". We next study the changes of radiation fluxes at the "surface" and the feedbacks associated with water vapor, cloud and surface albedo. As ozone concentration in the stratosphere and troposphere decreases, more solar radiation reaches the surface. However, less longwave radiation is emitted from the atmosphere to the surface. Changes of surface air temperature mainly depend on the net effect between changes in shortwave and longwave radiation.

Figure 5 shows changes of the shortwave radiation fluxes absorbed by the surface, downward longwave radiation fluxes, and the net radiation fluxes (shortwave pluses longwave) under clear-sky conditions, as $\mathrm{O}_{3}$ concentration is reduced from $100 \%$ to $50 \%$. In global and annual mean, surface absorption of shortwave radiation is increased by $1.1 \mathrm{~W} \mathrm{~m}^{-2}$, while downward longwave radiation is decreased by $-2.5 \mathrm{~W} \mathrm{~m}^{-2}$. The net change in radiation flux is $-1.4 \mathrm{~W} \mathrm{~m}^{-2}$, which is much larger than that at the tropopause $\left(-0.5 \mathrm{~W} \mathrm{~m}^{-2}\right)$, mainly due to reductions of tropospheric ozone and water-vapor feedback. As the ozone concentration is reduced, surface and air temperatures decrease and thus less water vapor can be maintained in the air, weakening the greenhouse gas effect and further cooling the surface.

In the Snowball Earth simulations being reported herein, because sea-ice thickness and coverage are fixed as described in Sect. 2, there is no ice-albedo feedback. However, there nevertheless exists snow-albedo feedback. As surface temperature decreases due to $\mathrm{O}_{3}$ reduction, snow depth and/or snow coverage increase. This results in an increase in surface albedo, which consequently causes less solar absorption and further surface cooling, constituting a positive feedback. It follows from Fig. 6a and $b$ that, as $\mathrm{O}_{3}$ concentration is reduced from $100 \%$ to $50 \%$, snow depth and surface albedo all increase. The increase of global-mean snow depth is approximately $0.001 \mathrm{~m}$, and the increase of global-mean surface albedo is approximately $0.2 \%$. The increase in surface albedo is associated with an approximately $0.5 \mathrm{~W} \mathrm{~m}^{-2}$ solar radiation reflected back to space (Fig. 6c). In Fig. 6b, the increase in surface albedo peaks at $45^{\circ} \mathrm{S}$ and $45^{\circ} \mathrm{N}$ around the snow line, with albedo increases of approximately $5 \%$ and $1 \%$, respectively. These locations of the maximum increases 

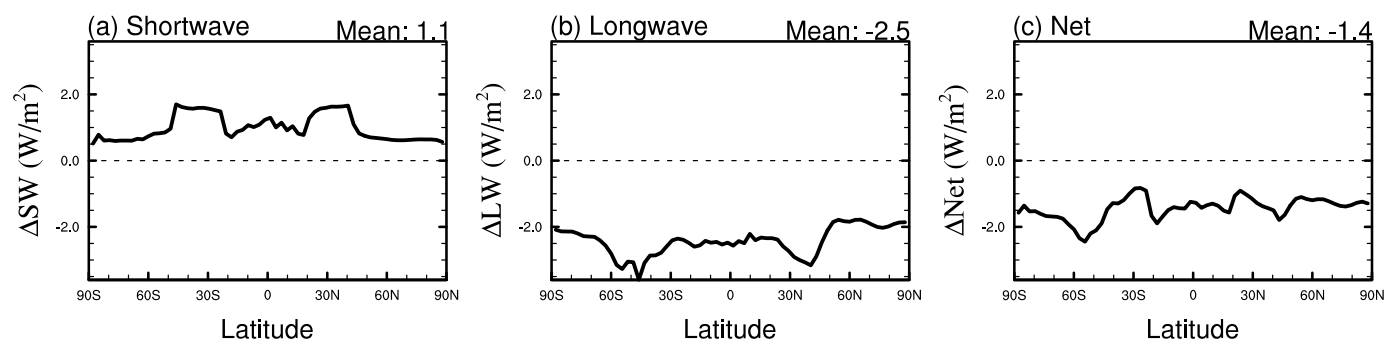

Fig. 5. Changes of surface-absorbed shortwave radiation fluxes (a), downward longwave radiation fluxes (b) and net fluxes (c, i.e. shortwave pluses longwave) for the case of $50 \%$ ozone, relative to the control experiment with unperturbed ozone. All of the values are for annual- and zonal-mean under clear-sky conditions. The $\mathrm{CO}_{2}$ level is 100 ppmv. Positive/negative values indicate warming/cooling effect. Global-mean value is shown at the right top of each panel. In the calculations, the influences of snow-albedo feedback (Fig. 6 below) are excluded.
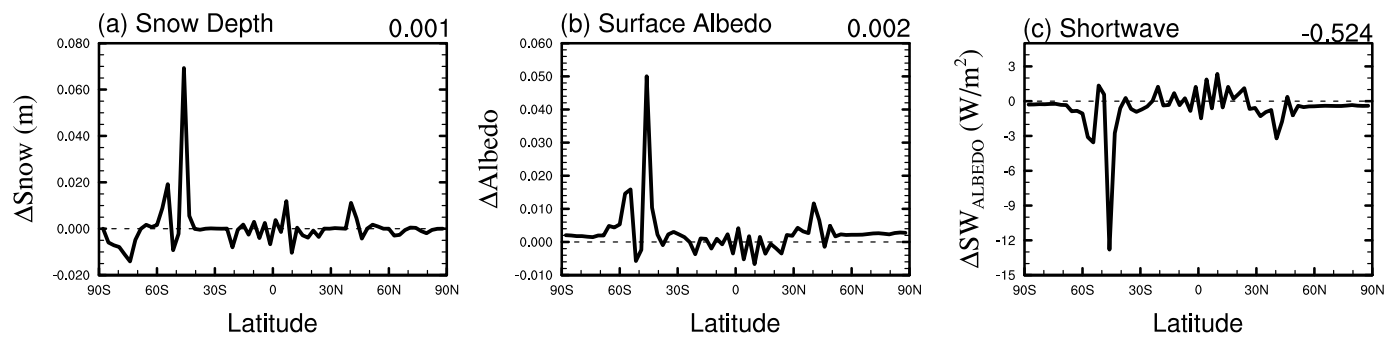

Fig. 6. Changes of snow depth (a), surface albedo (b), and absorbed shortwave fluxes (c) due to changes of surface albedo for the case of $50 \%$ ozone, relative to the control experiment. All of the values are for annual- and zonal-mean under clear-sky conditions. The $\mathrm{CO}_{2}$ level is 100 ppmv. Global-mean value is shown at the right top of each panel.

in surface albedo are consistent with those of the largest increases in snow depth (Fig. 6a) and the largest surface temperature decreases (Fig. 2a), indicating that the positive snow-albedo feedback is strongest in these regions. The reason why the feedback is strongest in these two regions is because they are associated with upward atmospheric motions, which leads to prevailing snowfall; thus, the snow-albedo feedback cycle is most active.

To further test the effect of snow-albedo feedback, we performed experiments with snow-free sea-ice on the surface. In the absence of snow-albedo feedback, it is found that the decrease in surface air temperature is by a factor of two smaller than that in the corresponding experiments with snow-albedo feedback, 0.4 vs. $0.8 \mathrm{~K}$ in global mean for the experiment of $100 \mathrm{ppmv} \mathrm{CO}_{2}$. This suggests that snow-albedo feedback greatly enhances the radiative effect of $\mathrm{O}_{3}$ changes on surface climate, as found in polar regions in the case of $\mathrm{CO}_{2}$-induced global warming (e.g. Hall, 2004).

A decrease in $\mathrm{O}_{3}$ concentration also causes changes of cloud properties, such as cloud coverage and cloud water path. Cloud changes consequently alter radiative forcing. As the $\mathrm{O}_{3}$ concentration is decreased from $100 \%$ to $50 \%$, both the liquid-cloud and ice-cloud water paths decrease due to decreases of air temperature and weakness of convection, especially in the regions where the atmosphere has upward motions (Fig. 7). Decreases of liquid-cloud water path weaken the radiative effect of low-level clouds, which generally has
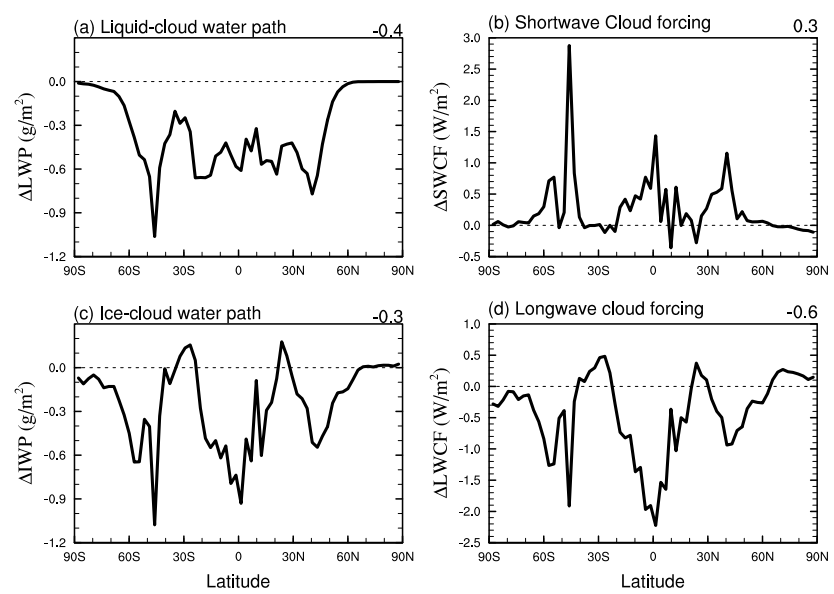

Fig. 7. Changes of liquid-cloud water path (a), surface shortwave cloud forcing (b), ice-cloud water path (c) and surface longwave cloud forcing (d) between $50 \%$ ozone reduction and the control experiment. The $\mathrm{CO}_{2}$ level is $100 \mathrm{ppmv}$. Global-mean value is shown at the right top of each panel.

a cooling effect on the surface by reflecting solar radiation back to space. Decreases of ice-cloud water path weaken the radiative effect of high-level clouds, which generally has a warming effect on the surface by absorbing infrared radiation from the surface and re-emitting it back to the surface. As a result, shortwave cloud forcing (SWCF, negative) 

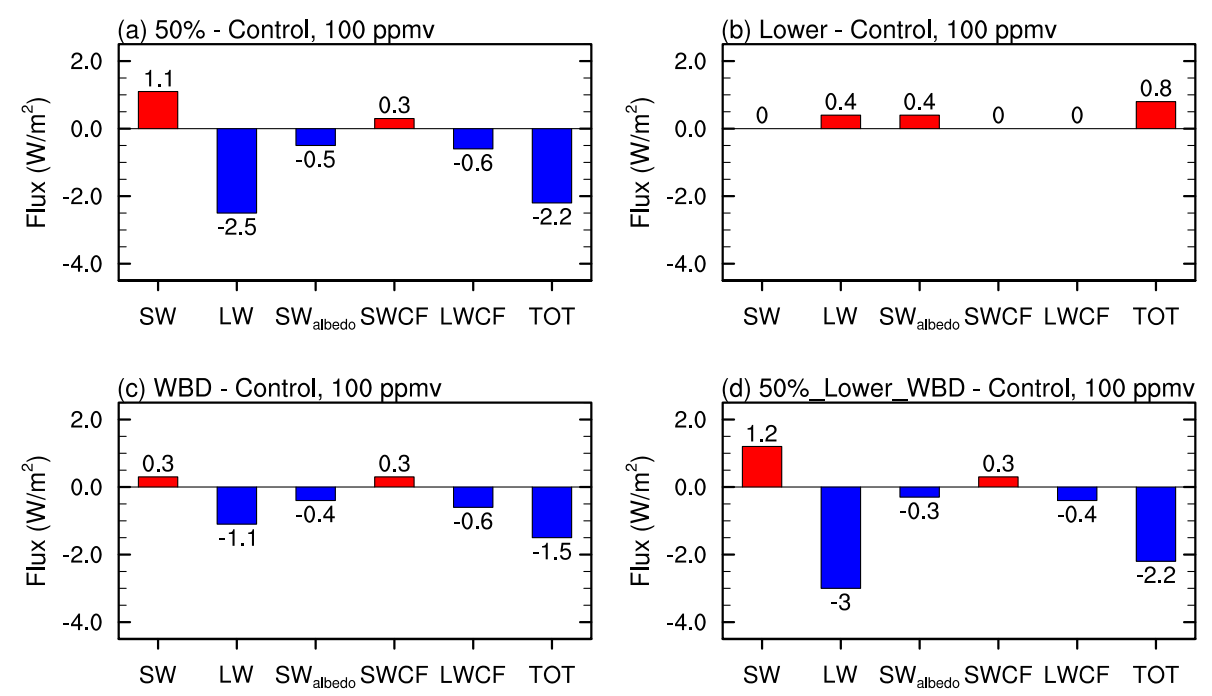

(e) 50\%_Lower_WBD - Control, $0.1 \mathrm{bar}$

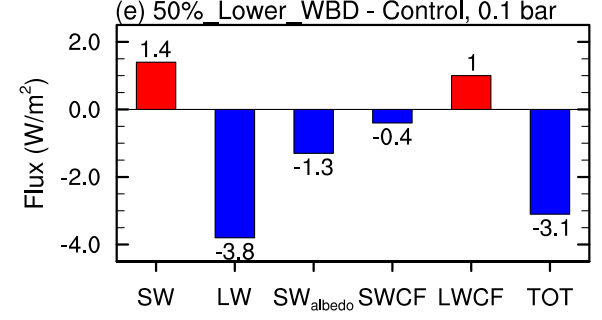

Fig. 8. Changes of surface radiative fluxes in global and annual mean between various ozone scenarios and control experiments. SW is surface-absorbed shortwave flux under clear-sky conditions, excluding the influence of snow-albedo feedback ( $\mathrm{SW}_{\text {albedo }}$ ). LW is surface downward longwave flux under clear-sky conditions. SWCF and LWCF are surface cloud radiative forcing in the shortwave and longwave bands, respectively. TOT is the sum of SW, LW, SW albedo, SWCF and LWCF. $\mathrm{CO}_{2}$ concentration is 100 ppmv in (a-d) and 0.1 bar in (e).

increases and acts a warming effect, whereas longwave cloud forcing (LWCF, positive) decreases and acts a cooling effect. In global and annual mean, changes of SWCF, LWCF, and the net cloud forcing (SWCF pluses LWCF) are $0.3,-0.6$ and $-0.3 \mathrm{~W} \mathrm{~m}^{-2}$, respectively. The cloud-radiation feedback therefore acts to further cool the surface.

As summarized in Table 1 and Fig. 8, surface radiation flux changes due to a $50 \% \mathrm{O}_{3}$ reduction under clearsky conditions, due to snow-albedo feedback, and due to cloud-radiation feedback are $-1.4,-0.5$, and $-0.3 \mathrm{~W} \mathrm{~m}^{-2}$, respectively. The total change of surface energy input is $-2.2 \mathrm{~W} \mathrm{~m}^{-2}$, and the change of global-mean surface air temperature is $-0.8 \mathrm{~K}$. The value of $-1.4 \mathrm{~W} \mathrm{~m}^{-2}$ includes two parts: reduction of stratospheric ozone $\left(-0.5 \mathrm{~W} \mathrm{~m}^{-2}\right)$, and decreases of tropospheric ozone and water vapor $\left(-0.9 \mathrm{~W} \mathrm{~m}^{-2}\right)$.

\subsection{Ozone effect on Snowball-Earth deglaciation}

In above simulations, the $\mathrm{CO}_{2}$ level for the purpose of all analyses was fixed to $100 \mathrm{ppmv}$, which approximately represents the Snowball climate state or the time of its formation. In the following, we show simulation results with 0.1 bar of
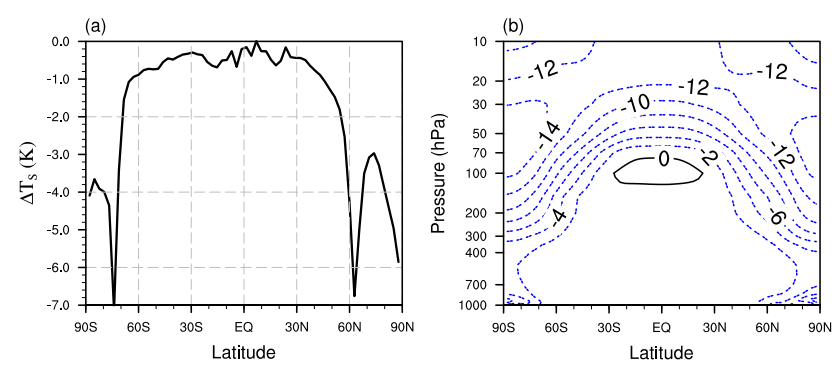

Fig. 9. Changes of annual- and zonal-man (a) surface temperature and (b) air temperature between the 50\%_Lower_WBD scenario and the control experiment. The $\mathrm{CO}_{2}$ level is 0.1 bar.

$\mathrm{CO}_{2}$, which roughly represents the climate state close to the onset of deglaciation of the Snowball Earth. The major difference between 100 ppmv and 0.1 bar of $\mathrm{CO}_{2}$ experiments is that the latter represents a much warmer climate. In this case, the global- and annual-mean $T_{\mathrm{S}}$ is approximately $250 \mathrm{~K}$, in contrast to $220 \mathrm{~K}$ for $100 \mathrm{ppmv}$ of $\mathrm{CO}_{2}$ (Hu et al., 2011a).

Figure 9 shows temperature differences between the "50\%_Lower_WBD" scenario and the control experiment 
with 0.1 bar of $\mathrm{CO}_{2} . T_{\mathrm{S}}$ is decreased by about $0.4 \mathrm{~K}$ in the tropics and by greater values at middle and high latitudes (Fig. 9a). The largest decrease is about $-7 \mathrm{~K}$ in polar regions, where the snow-albedo feedback is more active, as discussed above. The global- and annual-mean surface temperature decrease is $-1.0 \mathrm{~K}$ (Table 1), somewhat stronger than that in the case of $100 \mathrm{ppmv}$ of $\mathrm{CO}_{2}$. Comparison of Fig. 8e with Fig. 8d indicates that the decrease in total radiative fluxes on the surface is larger for $0.1 \mathrm{bar}$ of $\mathrm{CO}_{2}$ than that for $100 \mathrm{ppmv}$ of $\mathrm{CO}_{2}$, i.e. -3.1 vs. $-2.2 \mathrm{~W} \mathrm{~m}^{-2}$, although the reduction of radiation flux at the tropopause is nearly the same $\left(-0.5 \mathrm{~W} \mathrm{~m}^{-2}\right.$; see Table 1$)$. This is because in the much warmer climate the air contains more water vapor, and the same amount of $\mathrm{O}_{3}$ reduction would lead to further decreases in water vapor and thereby stronger watervapor feedback. Thus, the decrease in downward longwave radiation at the surface under clear-sky conditions is greater in the warmer climate $\left(-3.8\right.$ vs. $\left.-3.0 \mathrm{~W} \mathrm{~m}^{-2}\right)$, while the increase in shortwave radiation absorbed by the surface is also greater $\left(1.4\right.$ vs. $\left.1.2 \mathrm{~W} \mathrm{~m}^{-2}\right)$. The snow-albedo feedback is also stronger $\left(-1.3\right.$ vs. $\left.-0.3 \mathrm{~W} \mathrm{~m}^{-2}\right)$ because the water cycle is more active in the warmer climate, and air temperatures decreased by the same $\mathrm{O}_{3}$ reduction would lead to more snow accumulated on the surface, especially in polar regions.

$\mathrm{O}_{3}$ reduction leads to opposite signs of cloud forcing changes for both longwave and shortwave radiation in the two climate states. For $100 \mathrm{ppmv}$ of $\mathrm{CO}_{2}$, the $\mathrm{O}_{3}$ reduction caused a positive shortwave cloud forcing $\left(0.3 \mathrm{~W} \mathrm{~m}^{-2}\right)$ and a negative longwave cloud forcing $\left(-0.6 \mathrm{~W} \mathrm{~m}^{-2}\right)$. In contrast, the change of cloud forcing in the warmer climate is $-0.4 \mathrm{~W} \mathrm{~m}^{-2}$ for shortwave radiation and $1.0 \mathrm{~W} \mathrm{~m}^{-2}$ for longwave radiation. In the warmer climate state, $\mathrm{O}_{3}$ reduction tends to increase both ice and water clouds, and it is opposite to that in the colder climate state with $100 \mathrm{ppmv} \mathrm{CO}_{2}$, in which there is much less water vapor. In the warmer climate conditions, the increase in ice clouds tends to enhance longwave cloud forcing, while the increase in water clouds tends to decrease shortwave cloud forcing. As a result, longwave cloud forcing is increased by about $1.0 \mathrm{~W} \mathrm{~m}^{-2}$, while shortwave cloud forcing is decreased by about $0.4 \mathrm{~W} \mathrm{~m}^{-2}$, and the positive net cloud forcing of $0.6 \mathrm{~W} \mathrm{~m}^{-2}$ acts to warm the surface. The results of the relatively warm climate simulations are qualitatively consistent with the results for the present climate in Jenkins (1999), but the magnitude of cloud radiative forcing is much smaller. The difference is primarily due to the fact that cloud water path under the extremely cold Snowball Earth climate state is much less than that under present-day conditions, approximately 1.0 vs. $6.0 \mathrm{~g} \mathrm{~m}^{-2}$.

\section{Conclusions}

We have studied the radiative effect of the ozone layer on the climate of a hard Snowball Earth, by analysing the expected impacts of ozone concentration variations and spatial distributions. It is found that reduction in $\mathrm{O}_{3}$ concentration can significantly lower the surface temperature of a hard Snowball Earth. $\mathrm{As}_{3}$ is reduced by $50 \%$, the surface temperature is decreased by about $1.0 \mathrm{~K}$ for both $100 \mathrm{ppmv}$ and 0.1 bar of $\mathrm{CO}_{2}$. The maximum decreases of surface temperature occur at middle and high latitudes, with values as high as 4-7 K. These indicate that the value of $\mathrm{CO}_{2}$ threshold would be lower for Snowball Earth formation, but higher for Snowball Earth deglaciation, when the radiative effect of $\mathrm{O}_{3}$ is taken into account. In particular, the $\mathrm{CO}_{2}$ threshold must be lowered by half of the previous results for Snowball Earth formation, and the $\mathrm{CO}_{2}$ threshold in previous works for melting a hard Snowball Earth has to be higher by about one-third because doubling $\mathrm{CO}_{2}$ from 0.1 to 0.2 bars causes a $2-3 \mathrm{~K}$ increase in global-mean surface temperature (Pierrehumbert, 2004, 2005; Le Hir et al., 2007; Hu et al., 2011a). The results discussed herein also have important implications for the understanding of modern climate change issues related to ozone depletion in the last $20 \mathrm{yr}$ of the 20th century and likely ozone recovery in the 21 st century, especially for climate change in the Arctic and Antarctic where snow and ice albedo feedbacks are important and climate conditions are close to those considered in our simulations.

Our diagnoses show that the decrease in radiation fluxes from the stratosphere to the troposphere caused by $\mathrm{O}_{3}$ reduction is relatively small, approximately $-0.5 \mathrm{~W} \mathrm{~m}^{-2}$ in the global-and annual mean. However, the net change in radiation fluxes at the surface is about 4-6 times greater than that at the tropopause, about $-2.2 \mathrm{~W} \mathrm{~m}^{-2}$ for $100 \mathrm{ppmv}$ of $\mathrm{CO}_{2}$ and $-3.1 \mathrm{~W} \mathrm{~m}^{-2}$ for the case of $0.1 \mathrm{bar}$ of $\mathrm{CO}_{2}$. The amplification of radiation fluxes at the surface is primarily due to the action of feedback processes, such as those involving water vapor, snow albedo and clouds. Water vapor and snow albedo feedbacks significantly enhance the surface cooling. The sign of the cloud feedback in the shortwave band is opposite to that in the longwave band.

It is worth to note that the results here have uncertainties, depending on GCM model parameterizations of cloud radiative forcing and surface snow-ice albedo as well as feedback processes involved, while the results are qualitatively consistent with those from radiative-convective models that do not include parameterizations and feedbacks. In addition, the results here are also for hard Snowball-Earth conditions. For other types of Snowball-Earth models, such as the thin-ice model (McKay, 2000; Pollard and Kasting, 2005) or the Jormungand model (Abbot et al., 2011) that has much lower surface albedo in the tropics, ozone-induced changes in $\mathrm{CO}_{2}$ thresholds should be different. A final remark concerns the fact that we have focused our attention entirely upon idealized ozone scenarios. In future work it will be necessary to employ a fully interactive chemistry-climate model, with which the coupling of atmospheric oxygen, ozone and climate can be more realistically considered. 
Acknowledgements. We thank Yan Xia for helpful discussions. We also thank J. F. Kasting and M. Ishiwatari for their careful reviews and instructive comments, which help us improve the paper. Y. Hu and J. Yang are supported by the National Basic Research Program of China (973 Program, 2010CB428606) and the National Natural Science Foundation of China under Grant 41025018. J. Yang was partially supported by the Over-sea Study Program for Graduate Students of the China Scholarship Council. W. R. Peltier is supported by the Canadian Foundation for Climate and Atmospheric Science and a consortium of Canadian universities and by NSERC Discovery Grant A9627. The required computations were performed on the SciNet facility at the University of Toronto, which is a component of the Compute Canada HPC platform.

Edited by: Y. Godderis

\section{References}

Abbot, D. S. and Pierreuhumbert, R. T.: Mudball: surface dust and Snowball Earth deglaciation, J. Geophys. Res., 115, D03104, doi:10.1029/2009JD012007, 2010.

Abbot, D. S., Voigt A., and Koll, D: The Jormungand global climate state and implications for Neoproterozoic glaciations, J. Geophys. Res.-Atmos.,116, D18103, doi:10.1029/2011JD015927, 2011.

Briegleb, B. P., Bitz, C. M., Hunke, E. C., Lipscomb, W. H., Holland, M. M., Schramm, J. L., and Moritz, R. E.: Scientific description of the sea ice component in the Community Climate System Model version three, NCAR Tech. Note, NCAR/TN463+STR, 78 pp., 2004.

Chandler, M. and Sohl, L.: Climate forcings and the initiation of low-latitude ice sheets during the Neoproterozoic Varanger glacial interval, J. Geophys. Res.-Atmos., 105, 20737-20756, 2000.

Canfield, D. E.: The early history of atmospheric oxygen, Annu. Rev. Earth Pl. Sc., 33, 1-36, 2005.

Catling, D. C. and Claire, M. W.: How Earth's atmosphere evolved to an oxic state: a status report, Earth Planet. Sc. Lett., 237, 1-20, 2005.

Collins, W. D., Bitz, C. M., Blackmon, M. L., Bonan, G. B., Bretherton, C. S., Carton, J. A., Chang, P., Doney, S. C., Hack, J. J., Henderson, T. B., Kiehl, J. T., Large, W. G., Mckenna, D. S., Santer, B. D., and Smith, R. D.: Description of the NCAR Community Atmosphere Model (CAM 3.0), NCAR Tech. Note, NCAR/TN-464+STR, 214 pp., 2004.

Cordero, E. C. and Forster, P. M. de F.: Stratospheric variability and trends in models used for the IPCC AR4, Atmos. Chem. Phys., 6, 5369-5380, doi:10.5194/acp-6-5369-2006, 2006.

Donnadieu, Y., Godderis, Y., Ramstein, G., Nedelec, A., and Meert, J. G.: A "Snowball Earth" climate triggered by continental break-up through changes in runoff, Nature, 418, 303-306, 2004.

Fels, S. B., Mahlman, J. D., Schwarzkopf, M. D., and Sinclair, R. W.: Stratospheric sensitivity to perturbationisn ozone and carbon dioxide: radiative and dynamical response, J. Atmos. Sci., 37, 2265-2297, 1980.

Fishman, J., Ramanathan, V., Crutzen, P. J., and Liu, S. C.: Tropospheric ozone and climate, Nature, 282, 818-820, 1979.
Forster, P. M. de F. and Shine, K. P.: Radiative forcing and temperature trends from stratospheric ozone change, J. Geophys. Res., 102, 10841-10855, 1997.

Forster, P. M. de F., Johnson, C. E., Law, K. S., Pyle, J. A., and Shine, K. P.: Future estimates of radiative forcing due to tropospheric ozone change, Geophys. Res. Lett., 23, 3321-3324, 1996.

Gauss, M., Myhre, G., Isaksen, I. S. A., Grewe, V., Pitari, G., Wild, O., Collins, W. J., Dentener, F. J., Ellingsen, K., Gohar, L. K., Hauglustaine, D. A., Iachetti, D., Lamarque, F., Mancini, E., Mickley, L. J., Prather, M. J., Pyle, J. A., Sanderson, M. G., Shine, K. P., Stevenson, D. S., Sudo, K., Szopa, S., and Zeng, G.: Radiative forcing since preindustrial times due to ozone change in the troposphere and the lower stratosphere, Atmos. Chem. Phys., 6, 575-599, doi:10.5194/acp-6-575-2006, 2006.

Hoffman, P. F. and Schrag, D. P.: The Snowball Earth hypothesis: testing the limits of global change, Terra Nova, 14, 129-155, 2002.

Hoffman, P. F., Kaufman, A. J., Halverson, G. P., and Schrag, D. P.: A neoproterozoic Snowball Earth, Science, 281, 1342-1346, 1998.

Hall, A.: The role of surface albedo feedback in climate, J. Climate, 17, 1550-1568, 2004.

Holland, H. D.: The oxygenation of the atmosphere and oceans, Philos. T. Roy. Soc. B, 361, 903-915, 2006.

Holton, J. R., Haynes, P. H., McIntyre, M. E., Douglass, A. R., Rood, R. B., and Pfister, L.: Stratosphere-troposphere exchange, Rev. Geophys., 33, 403-439, doi:10.1029/95RG02097, 1995.

Hyde, W. T., Crowley, T. J., Baum, S. K., and Peltier, W. R.: Neoproterozoic Snowball Earth simulations with a coupled climate/icesheet model, Nature, 405, 425-429, 2000.

Hu, Y. and Tung, K.-K.: Possible ozone induced long-term change in planetary wave activity in late winter, J. Climate, 16, 30273038, 2003.

Hu, Y., Tung, K.-K., and Liu, J.: A closer comparison of early and late winter atmospheric trends in the Northern-Hemisphere, J. Climate, 18, 2924-2936, 2005.

Hu, Y., Yang, J., Ding, F., and Peltier, W. R.: Model-dependence of the $\mathrm{CO}_{2}$ threshold for melting the hard Snowball Earth, Clim. Past, 7, 17-25, doi:10.5194/cp-7-17-2011, 2011a.

$\mathrm{Hu}$, Y., Xia, Y., and Fu, Q.: Tropospheric temperature response to stratospheric ozone recovery in the 21 st century, Atmos. Chem. Phys., 11, 7687-7699, doi:10.5194/acp-11-7687-2011, $2011 \mathrm{~b}$.

Jenkins, G. S.: Examining the sensitivity of Earth's climate to the removal of ozone, landmasses and enhanced ocean heat transport in the GENESIS global climate model, Global Planet. Change, 20, 257-279, 1999.

Kirschvink, J. L.: Late proterozoic low-latitude global glaciation: the Snowball Earth, in: The Proterozoic Biosphere, edited by: Schopf, J. W. and Klein, C., Cambridge University Press, Cambridge, 51-52, 1992.

Lewis, J. P., Weaver, A. J., and Eby, M.: Snowball versus Slushball Earth: dynamic versus nondynamic sea ice?, J. Geophys. Res., 112, C11014, doi:10.1029/2006JC004037, 2007.

Liu, Y. and Peltier, W. R.: A carbon cycle coupled climate model of Neoproterozoic glaciation: influence of continental configuration on the formation of a "soft Snowball", J. Geophys. Res., 115, D17111, doi:10.1029/2009JD013082, 2010. 
Liu, Y. and Peltier, W. R.: A carbon cycle coupled climate model of Neoproterozoic glaciation: explicit carbon cycle with stochastic perturbations, J. Geophys. Res., 116, D02125, doi:10.1029/2010JD015128, 2011.

Le Hir, G., Ramstein, G., Donnadieu, Y., and Pierrehumbert, R. T.: Investigating plausible mechanisms to escape a Snowball-Earth, C.R. Geosci., 339, 274-287, 2007.

Le Hir, G., Donnadieu, Y., Krinner, G., and Ramstein, G.: Toward the Snowball Earth deglaciation. .. Clim. Dynam., 35, 285-297, doi:10.1007/s00382-010-0748-8, 2010.

Li, D. and Pierrehumbert, R. T.: Sea glacier flow and dust transport on Snowball Earth, Geophys. Res. Lett., 38, L17501, doi:10.1029/2011GL048991, 2011.

McKay, C. P.: Thickness of tropical ice and photosynthesis on a snowball Earth, Geophys. Res. Lett., 27, 2153-2156, 2000.

Oka, A., Tajika, E., Abe-ouchi, A., and Kubota, K.: Role of the ocean in controlling atmospheric $\mathrm{CO}_{2}$ concentration in the course of global glaciations, Clim. Dynam., 37, 1755-1771, doi:10.1007/s00382-010-0959-z, 2010.

Peltier, W. R., Liu, Y., and Crowley, J. W.: Snowball Earth prevention by dissolved organic carbon remineralization, Nature, 450, 813-818, 2007.

Pierrehumbert, R. T.: High levels of atmospheric carbon dioxide necessary for the termination of global glaciation, Nature, 429, 646-649, 2004.

Pierrehumbert, R. T.: Climate dynamics of a Snowball Earth, J. Geophys. Res., 110, D01111, doi:10.1029/2004JD005162, 2005.

Pierrehumbert, R. T., Abbot, D. S., Voigt, A., and Koll, D.: Climate of the Neoproterozoic, Annu. Rev. Earth Pl. Sc., 39, 417-460, 2011.

Poulsen, C. J. and Jacob, R. L.: Factors that inhibit Snowball Earth simulation, Paleoceanography, 19, PA4021, doi:10.1029/2004PA001056, 2004.

Poulsen, C. J., Pierrehumbert, R. T., and Jacob, R. L.: Impact of ocean dynamics on the simulation of the Neoproterozoic "Snowball Earth", Geophys. Res. Lett., 28, 1575-1578, 2001.

Pollard, D. and Kasting, J. F.: Snowball Earth: A thin-ice model with flowing sea glaciers, J. Geophys. Res., 110, C07010, doi:10.1029/2004JC002525, 2005.
Ramanathan, V. and Dickinson, R. E.: The role of stratospheric ozone in the zonal and seasonal radiative energy balance of the earth-troposphere system, J. Atmos. Sci., 36, 1084-1104, 1979.

Ramaswamy, V., Schwarzkopf, M. D., and Randel, W. J.: Fingerprint of ozone depletion in the spatial and temporal pattern of recent lower-stratospheric cooling, Nature, 382, 616-418, 1992.

Segura, A., Krelove, K., Kasting, J. F., Sommerlatt, D., Meadows, V., Crisp, D., Cohen, M., and Mlawer, E.: Ozone concentrations and ultraviolet fluxes on Earth-like planets around other stars, Astrobiology, 3, 689-708, 2003.

Tajika, E.: Faint young Sun and the carbon cycle: implication for the Proterozoic global glaciations, Earth Planet. Sc. Lett., 214, 443-453, 2003.

Voigt, A. and Marotzke, J.: The transition from the present day climate to a modern Snowball Earth, Clim. Dynam., 35, 887-905, 2010.

Voigt, A., Abbot, D. S., Pierrehumbert, R. T., and Marotzke, J.: Initiation of a Marinoan Snowball Earth in a state-of-the-art atmosphere-ocean general circulation model, Clim. Past, 7, 249263, doi:10.5194/cp-7-249-2011, 2011.

Wang, W.-C., Liang, X.-Z., Dudek, M. P., Pollard, D., and Thompson, S. L.: Atmospheric ozone as a climate gas, Atmos. Res., 37, 247-256, 1995.

Yang, J., Peltier, W. R., and Hu, Y.: The initiation of modern "soft Snowball" and "hard Snowball" climates in CCSM3, Part I: The influence of solar luminosity, $\mathrm{CO}_{2}$ concentration and the seaice/snow albedo parameterization, J. Climate, 25, 2711-2736, 2012a.

Yang, J., Peltier, W. R., and Hu, Y.: The initiation of modern "soft Snowball" and "hard Snowball" climates in CCSM3, Part II: Climate dynamic feedbacks, J. Climate, 25, 2737-2754, 2012 b.

Yang, J., Peltier, W. R., and Hu, Y.: The initiation of modern soft and hard Snowball Earth climates in CCSM4, Clim. Past, 8, 907-918, doi:10.5194/cp-8-907-2012, 2012c. 